\section{A Meeting on Technology arising from High Energy Physics}

\section{Geneva, Switzerland, 24-27 April 1974}

The aim and style of this meeting held at CERN in Geneva, 24-27 April 1974 , is best described in quoting M.G.N. Hine who has been the driving force of this gathering.

Firstly, we wanted to give an objective account of aspects of our work which do not, perhaps, get as well reported as do our physics results, particularly not to those of our Member State authorities and their advisers who are more interested in the industrial or technical consequences of laboratories like CERN than in their scientific output. We have seen this interest appear in the past particularly when large projects like the $300 \mathrm{GeV}$ accelerator came up for decision, but it has also then appeared that no one, on either side, is very clear on what technical consequences can or cannot reasonably be expected. A factual presentation of what actually has been done might help to clarify some of these uncertainties.

Secondly, since we are making this presentation to an audience containing many people very well able to make judgements on what they see, we hope to be able to benefit from an exchange of ideas and from the stimulus of your comments on the interest of what we are showing.

Thirdly, we hope that, in inviting to CERN people who come here in-

frequently, or not at all, we can improve our communications with the outside world in technological and industrial, as opposed to scientific, fields. Perhaps, because we are so busy keeping open house for the high energy physics community from all over the world, we tend to put a lower priority on listening to what people not directly in our business are saying, and that may not be too healthy in the long term.

The subject of the meeting was the technology arising from the European high energy physics programme, therefore not only from the work done at CERN but also from the work in national institutes all over Europe.

The mornings were devoted to review talks, the afternoons being free for visits to the exhibition stands spread over the CERN site.

W. Jentschke, Director-General of CERN Laboratory I, opened the meeting welcoming the participants.

J.B. Adams, Director-General of CERN Laboratory II, in a special session, described - as an example of European collaboration - the $300 \mathrm{GeV}$ accelerator at present built at CERN. L. van Hove gave an after-dinner talk on the current state of high energy physics.

The review talks treated a great variety of subjects:

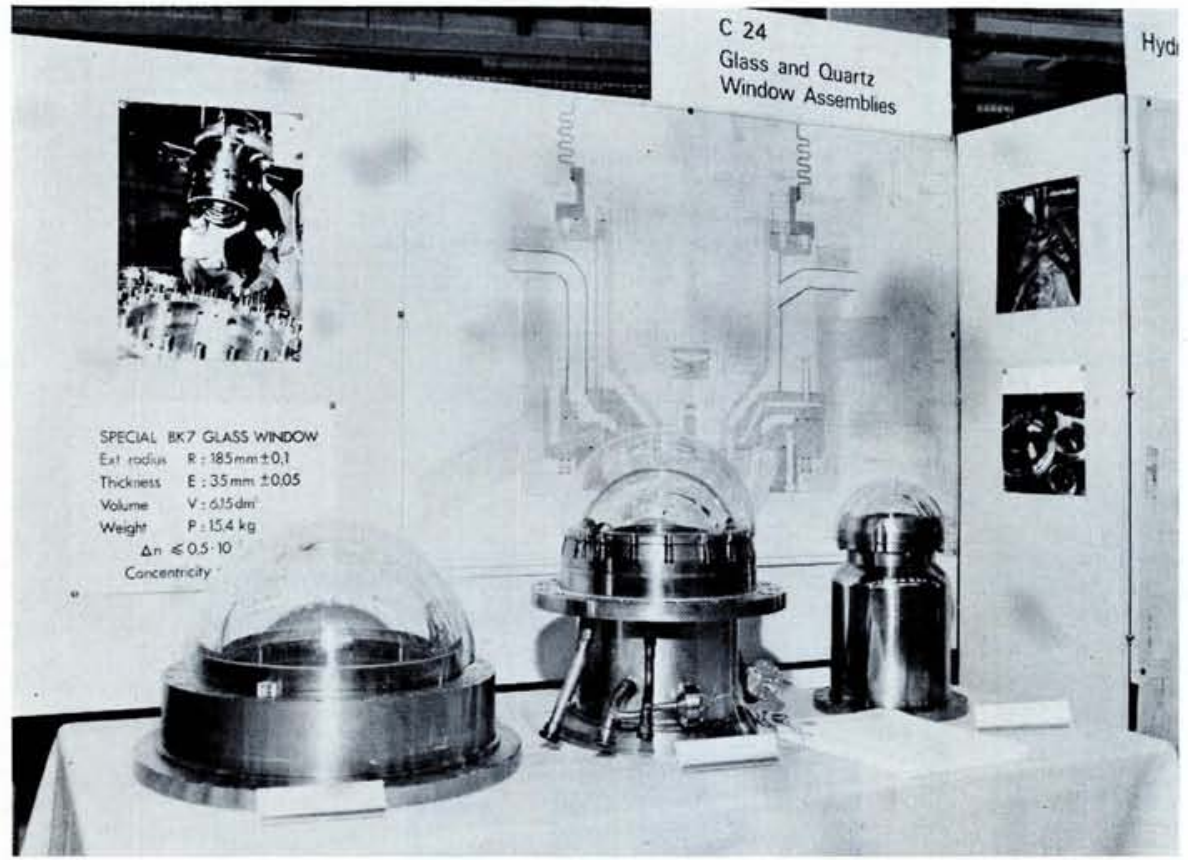

Hemispherical glass windows on metal support as used in the Large European Bubble Chamber (BEBC) are made of glass with particularly uniform refractive index or Herasil top quality quartz and withstand temperature variations between $300 \mathrm{~K}$ and $25 \mathrm{~K}$.
- Magnetic and electrostatic deflecting devices - Particle detectors

- Superconductivity

- Cryogenics

- Ultra high vacuum

- Realization of high energy projects in CERN - Computer control applied to accelerators - Synchrotron Radiation

- The precision surveying of large installations - The handling of data from experiments

It was pointed out that the high energy physics programme and CERN in particular, have stimulated in Europe technological fields like superconductivity and ultra high vacuum.

For instance, studies of large equipment with d.c. and pulsed magnets has led to the construction of large superconducting d.c. magnets. Models of pulsed magnets using very thin (some 10 microns) superconducting wire of Niobium-Titanium were also developed.

Another example of a stimulus in technology has been the design and construction of the $1 \mathrm{Km}$ vacuum tank at an average pressure of $10^{-11}$ Torr for the Intersecting Storage Rings at CERN. With its $40 \mathrm{~m}^{3}$ this tank is one of the biggest in the world and surely the longest at such a low pressure.

It was stressed that though the stimulus came from the community of high energy physics, most of the final developments and constructions in the two fields mentioned were done by industry.

The other fields with technological fall-out range from data processing and computer controls of large equipments to the use of synchrotron radiation produced by electron synchrotrons as a light source for special spectrometry.

A much awaited talk, and which did not deceive the audience, was the one of C.J. Zilverschoon, Director of the Proton Synchrotron Department. He explained the CERN philosophy in manning large projects and the CERN policy for placing the contracts with industry. Industry constructs some $95 \%$ of CERN equipment, most of the contracts falling either in the field of classical industry products or, in the extension to CERN needs, of classical ones.

A class of equipment nevertheless remains, which normally is not made by industry and for which CERN insists to have its own experts and design offices. Since such an equipment is practically always modified once it has been put in service, and since expert staff is needed to run and to maintain it, this policy is quite justified.

For this type of equipment, precise specifications are therefore drawn permitting a very competitive tendering all over Europe. It was stressed 
that this policy was only possible thanks to the flexible financial rules which were set up at the beginning of CERN by its Council; CERN is for instance not bound by a clause of "juste retour" and therefore has only to stick to the "best equipment for the lowest price" rule.

C.J. Zilverschoon mentioned an investigation currently under way at CERN to find out the economic utility of the technological fall-out for the industries in Europe. This interesting work is carried out by $\mathrm{H}$. Schmied in close collaboration with the industries and has shown that - excluding the contract itself - certain industries have benefited from the collaboration with CERN: acceleration of certain technological developments, cutting in some research costs, new markets, etc... This might explain why - with rather few exceptions - the European firms have accepted the CERN philosophy in conducting large projects.

A guided tour on the first afternoon gave an overall view of CERN and its big installations. On the two other afternoons, the participants toured freely around the exhibits.

About 250 stands were spread over Laboratory I and Laboratory II sites. The exhibits had been divided into eight categories listed hereafter:

- Beams and radiation

- Cryogenics and superconductivity

- Data processing

- Electronics

- Magnets and electricity

- Photography and optics

- Vacuum

- Workshop techniques and general engineering

Associated with each exhibit a 2-3 pages "Technology Note"» had been prepared for distribution, conveying the relevant information as well as the names of the people to be contacted for further information.

M. Peter, of the University of Geneva, and member of the Organizing Committee concluded the meeting summarizing the opinion of most of the participants; he stressed that:

1. The meeting was timely and has shown how truly advanced technology might influence science breakthrough.

2. It has been useful in stimulating and exchanging ideas and that the effort should be pursued.

3. The organization and the talks were good, the exhibits were very rich, well prepared and explained by a most helpful staff.

P. Germain, CERN

* The notes and a special issue of the CERN COURRIER devoted to the conference may be obtained from Public Information Office, CERN, CH-1211 Geneva 23.

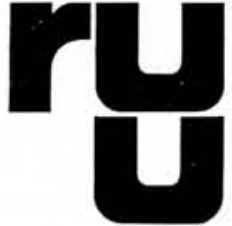

Rijksuniversiteit Utrecht

At the Department of Physics and Astronomy a position is vacant for a

\section{FULL PROFESSOR OF TECHNICAL PHYSICS}

who will undertake research and education in fields related to the energy problem, including its environmental aspects.

Applicants

should have conducted research of outstanding quality in physics or an allied discipline and should have shown actual interest, and preferably have participated in the above fields. Industrial or comparable experience would be an advantage. Candidates should be interested in interdisciplinary studies and have a capacity for, and preferably experience with teaching. Knowledge of the Dutch language is not a prerequisite.

Resources are available to develop an adequate research program to be carried out by Ph.D. candidates.

Salary and application
Details of the salary, of the conditions of service, and of the method of application, may be obtained by writing to

Professor C.Th.J. Alkemade, Physical Laboratory,

Sorbonnelaan 4, University, Utrecht, The Netherlands. (Tel. No. 030-533302)

\section{Society News}

Reduced rates of subscription are offered by the American Institute of Physics for the following publications:

- any of the three sections of Current Physics Advance Abstracts (CPAA) at US\$27.-

- any one of the three sections of Current Physics Titles (CPT) at US\$22.-

- to a combination of one CPAA and one CPT, at US\$ 45 .-

- Physics Today at US\$ 8.-

These rates include airfreight to Amsterdam and further distribution from there.

Subscriptions are to be addressed to David R. Dresia, American Institute of Physics, 335 East 45 Street, New York, N.Y. 10017.

\section{Individual Ordinary Members}

The following have been accepted as Individual Ordinary Members:

\footnotetext{
S. Ciulli, Bucharest

J.T.L. Dubois, Gothenburg

F.W. Felix, Berlin-West

I. Fischer-Hjalmars, Stockholm

R. Huber, Neuhausen-am-Rheinfall

D.O. Hummel, Cologne

E. Ingelstam, Stockholm

E. Källne, Uppsala

C. Kalbach, Gif-sur-Yvette

M.D. Kunisz, Cracow

J.-P. Lebet, Boudry

T. Lindblad, Åkersberga

T. Loennroth, Soukka

L. Matsson, Gothenburg

R. McMickle, Istanbul

B. Roos, Stockholm

S. Rydberg, Gothenburg

Z. Sawa, Stockholm

T. Shemaria, Haifa

M. Sundbom, Sollentuna

B. Stebler, Gothenburg

J. Thun, Uppsala
} 